\title{
Arrested Development e o Futuro das Séries (de Tevê?)
}

\author{
Marcel Vieira Barreto Silva \\ Professor Adjunto do Departamento \\ de Comunicação e do Programa de \\ Pós-graduação em Comunicação da \\ Universidade Federal da Paraíba. \\ Mestre e Doutor em Comunicação pela \\ Universidade Federal Fluminense. Autor \\ de "Adaptação Intercultural: o caso \\ de Shakespeare no cinema brasileiro" \\ (EDUFBA, 2013), e artigos e capítulos \\ de livros sobre narrativa, dramaturgia e \\ ficção seriada. \\ E-mail: marcelvbs@hotmail.com.
}

Resumo: Esta é a história de uma série de tevê que foi abruptamente cancelada e do serviço de streaming que surgiu para trazê-la das cinzas. Arrested Development foi uma série exibida entre 2003 e 2006 pela FOX, em canal aberto nos EUA, e se notabilizou por investir em estratégias narrativas e estilísticas pouco habituais à sitcom, como uma encenação mais realista e arco dramático metaficcional. O seu cancelamento causou alvoroço nos fãs, que ficaram anos em comunidades e redes sociais sonhando com o seu retorno. Ao realizar esse sonho, o Netflix trouxe de volta a série e colocou em pauta o futuro da ficção audiovisual seriada. O objetivo deste artigo é demonstrar como a estrutura narrativa da nova temporada ampliou a fruição televisiva sincrônica para a manipulação diacrônica da história, comum à internet. Isso é Arrested Development.

Palavras-chave: Arrested Development; Netflix; Ficção seriada; Streaming.

Abstract: This is a story about a TV series that was abruptly cancelled and about the streaming service that brought it from the ashes. Arrested Development was a TV series exhibited between 2003 and 2006 by FOX channel, an open TV channel, and that has been recognized for investing in narrative and stylistic strategies that are unusual in sitcoms, as a more realistic staging and metafictional dramatic arch. The cancellation of the series provoked bustle in the fans, who stayed years dreaming about its return on online communities and networks. Netflix made the dream come true, brought back the series and put on the agenda the future of serial audiovisual fiction. The aim of this paper is to show how the narrative structure of the new season has amplified the synchronic fruition of television to the diachronic manipulation of history, usual to the internet. This is Arrested Development.

Keyword: Arrested Development; Netflix; Serial fiction; Streaming.

\section{Introdução}

É Cinco de Quatro, um feriado inventado por Lucille Bluth para atrapalhar a vida da comunidade mexicana de Orange County, mas que, a contragosto da socialite, transformou-se em uma tradicional festa popular. Vemos Michael Bluth caminhar pela orla, margeando a festa, e ele demonstra estar arrasado. Sua dívida com Lucille Austero, em torno de 700 mil dólares, chegou ao limite e ele dispõe-se a pagá-la da maneira mais aviltante: sugere dormir com ela em troca da dívida. Após até essa solução sexual dar errado, ele retorna à casa modelo onde viveu com o filho por vários anos (e que imagina estar abandonada), e lá encontra GOB Bluth, seu irmão mais velho, que está com uma mulher misteriosa de quem vemos apenas os pés e as unhas pintadas. Michael se irrita com o irmão e este $o$ 
obriga a tomar um roofie, comprimido que apaga a memória no estilo "boa-noite cinderela". Há muito o que se esquecer, há a vergonha e a raiva e a chegada ao fundo do poço.

É um desfecho improvável para Michael, aquele que fora o filho mais centrado e talentoso da família Bluth. A necessidade de um flashback é pungente: seis meses antes, Michael dividia um beliche com seu filho George Michael, no campus da Universidade de Phoenix, onde o garoto aproveitava os anos de faculdade com a presença ostensiva e incomum de seu pai. Anos antes, quando do fim da terceira temporada de Arrested Development, Michael e seu filho escapavam de mais uma festa desastrada da família, fugindo em uma lancha pelo mar em direção ao sol. O que ocorreu nesse ínterim fica a cargo do narrador comentar: a tentativa de finalizar o projeto de Sudden Valley, um condomínio de mini-mansões em um descampado da Califórnia, deu absolutamente errado, porque coincidiu com a crise no mercado imobiliário norte-americano. Com um monte de casas para vender e ninguém para comprar, Michael teve que abandonar o empreendimento. Morar com o filho, na universidade, foi a última solução encontrada por ele. E é assim que começa a quarta temporada da série, produzida e exibida pelo Netflix diretamente para a internet.

Anos atrás, dificilmente poderíamos imaginar que o destino de Arrested Development seria um serviço de streaming de filmes e séries de tevê que só recentemente passou a investir em conteúdo próprio. Se fôssemos supor um possível e esperado retorno, nossa mente com certeza voltaria-se para os canais premium da televisão a cabo, como HBO, Showtime, AMC e mesmo FX, que se notabilizaram na última década por apresentar séries televisivas com estrutura narrativa complexa, personagens multidimensionais e deliberada mistura de gêneros - algo a que Arrested Development, mesmo produzida pela FOX, em canal aberto, sempre esteve associada. No entanto, ao trazer de volta um dos programas de televisão mais influentes e premiados da década passada, o Netflix buscou se inscrever em uma faixa de mercado voltada para produções segmentadas, com possibilidades de invenção antes só vistas nas melhores produções da televisão a cabo. Mas isso com um diferencial: todos os quinze episódios foram disponibilizados ao mesmo tempo, de modo que o espectador escolhia como, quando e em que ordem assistir aos episódios.

Neste artigo, queremos demonstrar como esse modo de distribuição da série influi diretamente na própria estrutura do programa, que radicaliza a sua metaficcionalidade através de um tour-de-force narrativo com um jogo de múltiplos pontos de vista sobre os mesmos eventos e um percurso temporal centrífugo repleto de analepses e prolepses. Antes da análise, porém, é importante caracterizar o momento atual de produção de séries, tido como mais uma época

${ }^{1}$ Na edição de março de 2013 da revista, há um longo dossiê sobre as séries de televisão no contexto atual, especialmente focado no caso de Arrested Development. O que chamam de Época de Platina da Televisão caracteriza-se por ser "hiper-social, com informação dirigida e aproximação do público com os atores e autores". Ou seja, é a síntese da produção seriada e sua circulação em plataforma digital. de ouro ou, para condizer com o termo apresentado pela revista $W_{i r e d^{1}}$, como a época de platina da televisão norte-americana.

\section{It's the final countdown: especificidades narrativas das séries contemporâneas}

As semanas de agosto e setembro passavam e a cada domingo a ansiedade aumentava: era a última temporada de Breaking Bad, série de Vince Gilligan exibida nos Estados Unidos pelo canal premium a cabo AMC. No Brasil, a série é exibida pelo canal AXN, subsidiário da SONY, mas com um pequeno problema: enquanto caminhava para os seus conflitos finais, Breaking Bad era exibida na nossa televisão com uma temporada de atraso. A derrocada moral de Walter White e a crise ética de Jesse Pinkman chegavam por aqui em seu habitat natural (ou seja, na televisão) com um delay desmedido, incongruente com o ambiente cultural contemporâneo em torno das séries de tevê e da sua facilidade de circulação pela internet.

Como tal, isso demonstra uma crise no modelo de negócio da televisão hoje em dia, em muitos casos ainda calcado em um modus operandi antiquado, incapaz 
${ }^{2}$ Temos que levar em conta o sucesso, na internet, de programas britânicos como Downtown Abbey, Sherlock, Luther e o lendário Doctor Who e de diversas séries orientais, especialmente as animadas, que possuem um amplo circuito de trocas, legendagem e distribuição de materiais (URBANO, 2012). de dar conta dos anseios dos espectadores brasileiros que não vão esperar um ano inteiro para ver o programa na televisão, se os episódios novos podem ser consumidos pela internet, por serviços de streaming legais (como o Amazon Instant Video) ou mesmo via torrent, através de incontáveis sites que disponibilizam séries e filmes para download. A HBO, por exemplo, já deu sinais da necessidade de operar transformações profundas nos modos de circulação dos seus produtos televisivos. Algumas de suas séries mais populares, como True Blood e Game of Thrones, tem seus episódios inéditos exibidos nos Estados Unidos e, ao mesmo tempo, em alguns mercados europeus e em mercados emergentes como Índia e Brasil. Ou seja, exibir os episódios inéditos de modo sincrônico, ao redor do mundo, denota a percepção da velocidade do circuito audiovisual através da internet e da necessidade de atender a essas novas demandas espectatoriais.

As séries de televisão, sejam elas de origem norte-americana ou não ${ }^{2}$, possuem um lugar destacado no cenário audiovisual, com obras narrativa e estilisticamente muito rebuscadas. Em termos de qualidade, é lugar comum hoje imputar a algumas dessas longas narrativas uma atenção crítica nunca antes vista. Fala-se da constituição de tramas e personagens complexos (MITTELL, 2006) ou mesmo de que essas séries são sintoma de uma ideologia reinante (JOST, 2012), segundo a qual o seu sucesso se sustenta por oferecer uma transparência do mundo representado, que se materializa em um benefício simbólico para o espectador.

Dizer que vivemos em uma época diferenciada no que se refere à produção e ao consumo de ficções seriadas audiovisuais implica na necessidade de apontar alguns elementos estruturantes que não existiam em outras épocas ou que, se existissem, possuíam características diferentes. Para além de critérios narrativos e estilísticos, David Buxton (2010) sugere que dois fatores são determinantes para explicar o sucesso das séries de televisão hoje:

A maturação dos canais a cabo (HBO, Showtime, AMC), menos limitados nos planos artístico e político (e são em geral as séries por eles produzidas que justamente se tornam objeto dos "seriéfilos"); e o consumo crescente de séries em outros suportes (DVD, download ou streaming na internet). (BUXTON, 2010: 09)

A esses fatores, de ordem econômica e técnica, podemos acrescentar outros dois, de ordem mais cultural e simbólica: a definição social do escritor-produtor como centro criativo de um programa produzido de forma coletiva, isto é, em um cenário com multi-canais e audiência extremamente fragmentada, a figura do escritorprodutor, alçado à categoria de autor, oferece aos programas uma marca distintiva que se associa à identidade da emissora enquanto uma marca (JOST, 2010: 51); além disso, a proliferação de espaços críticos sobre as séries de tevê, sejam eles sites, blogs ou mesmo revistas dedicados à análise e à crítica dos programas em geral ou de programas específicos. Dois exemplos são sintomáticos desse processo: no site Game of Thrones Br (www.gameofthronesbr.com) há diversos textos críticos, escritos por fãs da série literária e da televisiva, disponibilizados logo depois que os episódios vão ao ar. Porém, o grau de especialização é tanto que há dois tipos de críticas: para os que leram os livros e para os que estão vendo apenas a série de tevê. Com isso, informações adicionais e spoilers ficam resguardados unicamente a quem já conhece a história literária, garantindo a surpresa típica das mudanças bruscas na trama que tanto caracteriza Game of Thrones.

Outro exemplo vem de revistas de crítica de cinema que, inevitavelmente, são incitadas a desenvolver números especiais sobre as séries de tevê, com destaque para as norte-americanas de canais segmentados, tendo em vista a excelência desses programas perante o cenário audiovisual contemporâneo. Para ficar só com algumas, podemos citar as edições de julho-agosto de 2003 (Séries: L'age d'or) e de julho-agosto de 2010 (Séries: une passion américaine), da célebre revista 
francesa Cahiers du Cinéma, uma das principais responsáveis por encampar discussões críticas em torno do nascimento do cinema moderno nos anos 1950 e 60; ou a também francesa Positif, com seu número de setembro de 2011, que apresenta um dossiê intitulado Séries Américaines, com textos críticos sobre programas como True Blood, Dexter e Glee, e abordagens autorais de figuras como Matthew Weiner (roteirista de The Sopranos e criador de Mad Men) e J.J. Abrams (produtor das séries Lost, Fringe e Person of Interest); ou ainda a edição recente, de setembro de 2013, da revista britânica Sight and Sound, que, além de apresentar diversos programas de televisão realizados por diretores de cinema (de The Alfred Hitchcock Hour ao Medea de Lars Von Trier, de Twin Peaks de David Lynch e Mark Frost ao recente Top of the Lake de Jane Campion), analisa a fundo a chegada da última temporada de Breaking Bad, cujo criador, Vince Gilligan, nunca dirigiu um filme sequer.

Os elementos aqui apresentados ajudam a entender o cenário contemporâneo caracterizado como "cultura das séries" (SILVA, 2013), ou seja, um amplo circuito cultural que envolve os programas e suas estratégias estilísticas inovadoras, o contexto tecnológico que permite a ampla circulação transnacional e os modos de consumo e crítica textual novos, através de comunidades de fãs e críticas especializadas. A novidade que se apresentou com o Netflix, no entanto, foi não apenas a sua capacidade de fazer circular os programas em um serviço de streaming com alta qualidade, mas a sua aposta em programação original própria, capaz de competir com a televisão a cabo em termos de ousadia e inovação.

\section{Insert me anywhere: televisão, internet e os estilos de atuação do Dr. Tobias Fünke}

A televisão atualmente passa por mudanças estruturais em suas mais diferentes esferas. No plano tecnológico, a entrada da televisão digital e o crescente domínio no mercado de televisores smart introduzem novos regimes de espectatorialidade na experiência de assistir televisão, cada vez simultânea à utilização de uma segunda tela, seja de computadores, tablets ou celulares, e da escolha dos programas através de serviços de video on demand, que definem a televisão, conforme explicam Bolaños e Brittos (2007: 29), "como um portal multisserviços, relativos à eleição de cenas e à eliminação de trechos, ao lado de acesso à internet, comércio pela televisão (t-commerce), cupons eletrônicos e ampliação das informações".

No plano estilístico, a qualidade técnica da imagem digital - em contraposição com a sua história analógica - oferece um nível de depuração e de sofisticação que se revelam cada vez mais em decupagens inovadoras (Mad Men, Homeland e Breaking Bad são casos sintomáticos disso, mas já podemos perceber, como aponta Renato Pucci (2013), essas inovações em telenovelas brasileiras, como Avenida Brasil) e em efeitos de pós-produção que em nada devem a grandes blockbusters hollywoodianos (como é o caso dos tão comentados dragões de Game of Thrones). No plano econômico, a criação exponencial de novos canais e de novas ferramentas de circulação audiovisual, especialmente na última década, criaram uma disputa acirrada por um mercado cada vez mais segmentado. No caso norte-americano, os índices de audiência da televisão a cabo estão cada vez mais próximos da televisão aberta: o último episódio da terceira temporada de The Walking Dead, exibido pelo canal a cabo AMC, teve público de 13,4 milhões de pessoas, e a sua média em relação a um público de 18-49 anos (aquele mais visado pela publicidade) foi superior a séries muito populares de televisão aberta, como The Big Bang Theory e Modern Family, e mesmo aos antes imbatíveis reality shows, como American Idol e The Voice ${ }^{3}$. Tudo isso é sintoma de um período singular na história da televisão que, como aponta Arlindo Machado (2011), ainda vai exigir muita reflexão da parte dos pesquisadores:

${ }^{3}$ Sobre isso, consultar: http://www. deadline.com/2013/04/walking-deadratings-season-3-finale/ e http:// insidetv.ew.com/2013/07/27/nbc-thewalking-dead/ 
ainda não se sabe bem o que poderá vir a ser. Vamos viver um período de muita experimentação de novos modelos de televisão, onde alguns vingarão e outros provavelmente fracassarão. Tudo indica que estamos vivendo o fim de um modelo de televisão e o surgimento de experiências ainda não muito nítidas, mas suficientemente expressivas para demandar pesquisa e análise (MACHADO, 2011: 88).

No meio desse turbilhão de transformações, as séries de televisão norteamericanas parecem hoje ter encontrado uma síntese singular de interesse do público, repercussão crítica e retorno financeiro. A hipótese que estamos desenvolvendo em nossa pesquisa é que um dos motivos - e talvez o principal para esse sucesso é que as séries conseguiram, mais que qualquer outro produto audiovisual (e aí o cinema está anos-luz aquém), fazer da relação entre televisão e internet um trunfo determinante para o que antes lhe era um problema: o caráter nacional e sincrônico da transmissão dos sintagmas televisivos. Isso significa dizer que, mesmo que as séries importadas, vistas aqui pelo termo pejorativo de "enlatados" (BALOGH, 2001: 102), sempre estivessem presentes nas grades de programação da televisão brasileira desde o seu início, elas vinham como produtos de segunda mão, já exibidos em seus países de origem e retransmitidos aqui meses e mesmo anos depois. No entanto, com o processo de digitalização e com os circuitos criados na internet, as séries de tevê são hoje consumidas em nível global, ao mesmo tempo, com trocas de arquivos, legendas, comentários, críticas, recaps, vídeos de reação e mais um sem-números de práticas textuais, pictóricas e audiovisuais que ampliam o efeito semântico proporcionado por determinado episódio para durar a semana inteira até o episódio seguinte.

Nesse sentido, podemos categorizar a relação entre televisão e internet, no que se refere às séries de tevê, em três modos que, embora diferentes, estão muitas vezes imbricados nas práticas espectatoriais:

1. O modo aditivo - Televisão com a Internet: nesse caso, estamos falando de práticas discursivas que somam à experiência televisiva produtos que estão ofertados na internet, respeitando a singularidade de cada meio. Um exemplo disso são os websódios de séries de tevê que apresentam na internet eventos novos, ausentes dos programas televisivos, em uma linguagem e uma narrativa também específicos. Aqui, podemos citar programas como Lost, The Walking Dead e The Office, além do caso brasileiro da telenovela Cheias de Charme. É esse tipo de relação que está contida na ideia de transmidiação, conforme explicam Fechine e Figueirôa:

Como parte do esforço para manter e atrair públicos, as grandes emissoras de televisão começam a tirar proveito da convergência, investindo mais fortemente no emprego articulado de outras mídias para expansão da experiência televisiva, adotando um conjunto de estratégias conhecidas como transmidiação (FECHINE \& FIGUEIRÔA, 2011: 17).

2. O modo inclusivo - Televisão na Internet: refere-se à presença, através de mera transposição, de programas televisivos na internet. Nesse caso, estamos falando de diferentes práticas de consumo, que vão da compra de episódios esparsos em sites de oferta de video on demand ou de download, via torrent, de episódios, temporadas ou séries inteiras, em arquivos de diferentes compressões e qualidades (de .rmvb a .mkv). Além deles, é importante referenciar inúmeros serviços que disponibilizam séries para exibição na rede, sejam eles de modo oficial (como aqueles vinculados aos canais a cabo, tipo Muu, HBO Go e Telecine Play) ou de modo não-oficial (o site Watch Series (www.watchseries.It), por exemplo, que apresenta diversas séries, de diferentes países, para serem vistas, de graça, via streaming). 
${ }^{4}$ Sobre isso, consultar: http://www. deadline.com/2013/04/walking-deadratings-season-3-finale/ e http:// insidetv.ew.com/2013/07/27/nbc-thewalking-dead/
3. O modo exclusivo - Televisão da Internet: aqui, estamos abarcando as práticas televisivas que se dão apenas na internet, ou seja, não apenas fora do fluxo e da grade de programação das emissoras, mas através, inclusive, de modelos de negócio independentes. Nesse caso, podemos citar os canais do Youtube, com diferentes temporalidades de distribuição de material e mesmo de apresentação (há a possibilidade de transmissão ao vivo, por exemplo). Além disso, o conteúdo próprio criado por serviços de streaming como Hulu ou Netflix são sintomáticos de séries de televisão exclusivas da internet. House of Cards, uma das séries mais bem-sucedidas do Netflix, concorreu ano passado ao prêmio Emmy de melhor série de tevê, embora tenha sido distribuída apenas na internet.

Nas vésperas do lançamento da temporada de Arrested Development do Netflix, em maio de 2013, foi disponibilizada uma série de vídeos ${ }^{4}$ do personagem Tobias Fünke, um ex-médico e aspirante a ator com uma tendência a soltar trocadilhos homoeróticos, sobre uma tela verde de chroma key encenando algumas situações que revelam a sua imperícia artística como ator. O objetivo era o público pegar os vídeos e editá-los, inserindo o personagem em panos de fundo os mais variados, para partilha em redes sociais e sites de compartilhamento de vídeos. Como tal, o Netflix direciona sua estratégia de marketing para aqueles que já viram as temporadas anteriores (na televisão, em DVD, na internet ou no próprio Netflix). Ou seja, ao delimitar a capacidade de decodificação para aqueles que, em sua maioria, já conhecem os personagens e suas características cômicas, o Netflix denota o esforço de segmentação que aparece no seio da própria estrutura narrativa da nova temporada do programa. Arrested Development, em sua temporada na internet, radicaliza o esforço cognitivo exigido do espectador através de uma série de operações estilísticas como a metaficcionalidade, o jogo de pontos de vista e a recorrência a leitmotifs visuais e auditivos das temporadas anteriores. Embora esses elementos já tenham sido utilizados quando a série passava na televisão, eles se tornam mais radicais ao aumentar a tensão entre os arcos episódicos focados em determinados personagens e um arco seriado multiperspectivista.

\section{Cinco de quatro e os mil olhos de Lucille Bluth}

Para tentar entender a intrincada estrutura narrativa de Arrested Development, vamos recorrer a conceitos fundamentais da narratologia. No livro Discurso da Narrativa (1995), Gérard Genette procura estabelecer, a partir dos limites e dos problemas do processo de contar histórias, uma categorização que organize a análise nos seguintes segmentos: tempo (que se divide em ordem, duração e frequência), modo e voz. No caso de Arrested Development, essas três unidades conceituais da narratologia (tempo, modo e voz) articulam-se deliberadamente, misturando o percurso narrativo através de saltos e repetições de cenas (tempo), mudanças nos regimes de focalização (modo) e uso expressivo do narrador em off (voz). Para mostrar como funciona esse esquema, vamos discorrer sobre cada um desses elementos, usando trechos específicos da série para ilustrar a sua estrutura.

Os episódios da quarta temporada de Arrested Development diferem-se dos anteriores, em termos narrativos, basicamente por três elementos: arco episódico focado em um único personagem (isso se deu, além do interesse estilístico, pela dificuldade de agenda para juntar o elenco original em todos os episódios); falta de limites no seu tamanho (diferentemente dos episódios televisivos, que sempre possuem por volta de 22 minutos, para o Netflix os episódios variam entre 28 e 33 minutos); e uso de um arco seriado multiperspectivista, em que alguns eventos são apresentados em diferentes episódios, sempre através do ponto de vista de cada um dos personagens. Isso deu ao programa um ritmo novo, que se justifica pelo modelo de negócio do Netflix: por não ter intervalo comercial e por os episódios serem disponibilizados todos ao mesmo tempo, o jogo narrativo, aos moldes de Rayuela, do Cortázar, oferece-se para a construção do espectador cujo poder de interação com a trama, na internet, é determinante para a proposta narrativa da série. 
Dessa maneira, o tempo de Arrested Development é centrífugo, ou seja, escapa da ordem natural e estrutura-se a partir de idas e vindas no passado e no futuro. Esses percursos temporais são bancados pelo narrador em off - uma figura pouco usual no gênero da sitcom -, que avança (prolepse) e retrocede (analepse) no tempo dependendo da história que está sendo contada. Com isso, os episódios caracterizamse por tentar dar conta da vida do personagem em momentos determinados da história, momentos esses que se repetem com todos os personagens.

A festa de Cinco de Quatro, uma reunião familiar no apartamento de Lucille e George Bluth, três eventos simultâneos que ocorrem num mesmo hotel (a premiação dos Opies, o anúncio da candidatura de Herbert Love e o show de mágica de Tony Wonder) e o momento da prisão de Lucille depois de ela tomar posse do Queen Mary, são todos eventos narrativos que se mostram diversas vezes, por diferentes pontos de vista, de modo não hierarquizado que permite o espectador escolher o percurso que ele deseja fazer nos episódios da série. Esse procedimento estilístico é o que Genette chama de frequência, e se refere ao fato de que "uma narrativa, qualquer que ela seja pode contar uma vez o que se passou uma vez, $n$ vezes o que se passou $n$ vezes, $n$ vezes o que se passou uma vez e uma vez o que se passou n vezes" (GENETTE, 1995: 114).

Há um uso curioso de elementos específicos do universo da internet na própria mise-en-scène da série no que se refere à manipulação do tempo. Ao realizar saltos temporais longos na vida de uma personagem, a tela passa a se apresentar como uma página de reprodução de vídeo na internet, com a barra de rolagem abaixo do vídeo indicando as idas para frente e para trás no tempo. Além disso, quando as analepses apresentam imagens das temporadas antigas, aparece uma marca d'água com o título de Showstealer Pro Trial Version, um software ficcional capaz de roubar, com facilidade, trechos de programas televisivos. Esse uso autorreflexivo de elementos da internet na própria mise-en-scène é com certeza algo novo, mas que se assemelha ao modo como a série já fazia na televisão, propondo uma estrutura bastante moderna, em que a encenação procura o efeito cômico a partir da denúncia dos seus próprios procedimentos.

A construção de cada episódio a partir da focalização em determinado personagem é fundamental para a montagem da temporada na internet. Isso significa que, mesmo tendo um arco seriado amplo, que atravessa vários anos, a história de Arrested Development não vai "pra frente", mas gira em falso em torno da perspectiva de cada um dos personagens. Ao construir os episódios com focalização interna em diálogo com a presença de um narrador onisciente que comenta a ação e facilita as idas e vindas no tempo, a série garante os arcos episódicos que possibilitam a fruição esparsa tão comum à sitcom: ou seja, apesar de construir um arco seriado bastante intrincado, Arrested Development apresenta cada episódio como uma unidade, capaz de ser assistido de maneira autônoma. Na prática, alguns episódios funcionam mais do que outros na sua dimensão episódica (A New Start, Collony Collapses, A New Attitude e Señoritis são episódios brilhantemente construídos, capazes tanto de fazer o arco seriado progredir quanto de oferecer a fruição episódica própria da sitcom), mas o princípio narrativo construído é semelhante nos quinze episódios.

O jogo entre a voz do narrador em off e a focalização da história em determinados personagens é também um elemento importante de se destacar. $O$ efeito cômico - e também autorreflexivo - relacionado ao narrador é a presença na diegese de Ron Howard, um dos produtores responsáveis pelo programa e o dono da voz na própria narrativa. E ele faz o papel dele mesmo, como o produtor interessado em transformar a história da família Bluth em um filme. Na verdade, Howard já havia aparecido no fim da última temporada na televisão, propondo exatamente isso para a personagem Maeby, a sobrinha de Michael Bluth. Ou seja, ao aparecer novamente na temporada produzida para a internet, o personagem de Ron Howard 
${ }^{5} \mathrm{O}$ trabalho desenvolvido por Maria Immacolata Vassalo de Lopes (2011) e demais pesquisadores vinculados ao OBITEL já apresenta resultados de pesquisas que demonstram muito bem essa aproximação.

\footnotetext{
${ }^{6}$ Sobre isso, vale conferir os diversos textos organizados em Allrath \& Gymnich (2006).
}

(interpretado por ele mesmo e que, também, é a voz do narrador) estabelece uma entre as tantas pontes de significado entre a série televisiva e sua versão Netflix.

Para além da mera escolha estilística de usar esses procedimentos (a frequência repetitiva, a focalização múltipla e uso do narrador autorreflexivo), nosso argumento é de que a estrutura narrativa de Arrested Development no Netflix foi construída tendo em vista a própria natureza espectatorial do meio digital, mais especificamente o modo assíncrono com que o espectador se relaciona com o produto audiovisual e as possibilidades de interação do público na própria montagem da estrutura da temporada. Ou seja, Arrested Development, anteriormente já definida como uma série que apontava o futuro da sitcom (MILLS, 2009), mostra-se agora como um programa extremamente inovador, por fazer a transição entre televisão aberta e internet, construindo uma estrutura narrativa pensada para o novo meio. Dizer que a série aponta para como será o futuro da televisão talvez seja empolgação em excesso, mas com certeza ela ajuda a pensar que o campo dos estudos de televisão, atualmente, deve construir suas análises em sintonia com o campo da cibercultura ${ }^{5}$. Afinal, telas, janelas e narrativas que se interpenetram já fazem parte da televisão de hoje.

\section{Considerações finais}

Pensar na relação entre televisão e internet, no que se refere às séries de tevê, implica não apenas em perceber a evidência concreta das práticas culturais que dominam a produção, a circulação e o consumo audiovisual na contemporaneidade, mas sobretudo apontar para a necessidade de uma reflexão teórico-metodológica que permita à análise dos procedimentos narrativos e estilísticos de obras situadas nessa fronteira, uma envergadura hermenêutica que não oblitere as especificidades de cada campo. Ao recorrer a categorias oriundas da narratologia para investigar narrativas seriadas ${ }^{6}$, estamos apostando que a análise dos elementos estruturantes da linguagem audiovisual em questão pode ser útil para pensar no processo cultural mais amplo, no qual a relação entre televisão e internet impõe cada vez mais necessidade de reflexão.

Com isso, pensar Arrested Development como uma obra na vanguarda, experimentando elementos novos em consonância com a natureza do novo meio, pode ser um princípio de investigação para outras e mais aprofundadas análises. Depois de Arrested Development, o Netflix continuou lançando séries novas, de criadores oriundos da televisão, como Orange is the New Black, de Jenji Kohan (autora da polêmica Weeds, que teve oito temporadas no canal a cabo Showtime) e Derek, do comediante Rick Gervais (um dos criadores de The Office, certamente uma das sitcoms mais influentes da última década). No Brasil, inclusive, houve a primeira série do Netflix aqui, chamada $A$ Toca, também um exemplo para se pensar os trânsitos audiovisuais na internet, visto que a série repete a estrutura de vinheta e esquetes que o grupo Parafernália, responsável pelo programa, já há muito fazia em canais no Youtube. Mas, aí, já é outra conversa.

\section{Referências Bibliográficas}

ALLRATH, Gaby, GYMNICH, Marion. Narrative Strategies in Television Series. London, UK: Palgrave MacMillan, 2005.

BALOGH, Anna Maria. O Discurso Ficcional na TV. São Paulo: Edusp, 2002.

BOLAÑO, César Ricardo Siqueira, BRITTOS, Valério Cruz. A televisão brasileira na era digital: exclusão, esfera pública e movimentos estruturantes. São Paulo: Paulus, 2007. 
BUXTON, David. Les Séries Televisées: Forme, Ideologie et Mode de Production. Paris: L'Harmattan, 2010.

FECHINE, Yvana, FIGUEIRÔA, Alexandre. Transmidiação: explorações conceituais a partir da telenovela brasileira. In: LOPES, Maria Immacolata Vassalo de Lopes. (Org.). Ficção televisiva transmidiática no Brasil: plataformas, convergência, comunidades virtuais. Porto Alegre: Sulina, 2011, p. 17-59.

GENETTE, Gerárd. Discurso da Narrativa. 3. Ed. .Lisboa: Vega, 1995.

JOST, François. Compreender a televisão. Porto Alegre: Sulina, 2010.

Do que as séries americanas são sintoma? Porto Alegre: Sulina, 2012.

LOPES, Maria Immacolata Vassalo de Lopes. (Org.). Ficção televisiva transmidiática no Brasil: plataformas, convergência, comunidades virtuais. Porto Alegre: Sulina, 2011.

MACHADO, Arlindo. Fim da televisão? In: Revista Famecos, Porto Alegre, v. 18, n. 1, p. 86-97, janeiro/abril, 2011.

MILLS, Brett. The Sitcom. Edinburgh: Edinburgh University Press, 2009.

MITTELL, Jason. Narrative complexity in contemporary american television. The velvet light trap, n. 58, Texas: University of Texas Press, 2006. p. 29-40.

PUCCI, Renato. Inovações estilísticas na telenovela: a situação em Avenida Brasil. In: Encontro Anual da Compós, 22, 2013, Salvador. Anais... Salvador, Edufba, 2013. Disponível em: <http://www.compos.org.br/data/biblioteca_2079.pdf>. Acesso em: 03 set. 2013.

SILVA, Marcel Vieira Barreto. Cultura das séries: forma, contexto e consumo de ficção seriada na contemporaneidade. In: Encontro Anual da Compós, 22, 2013, Salvador. Anais.... Salvador, Edufba, 2013. Disponível em: <http://www.compos. org.br/data/biblioteca_2076.pdf>. Acesso em: 03 set. 2013.

URBANO, Krystal Cortez Luz. Fansubbers em cena: mediação e distribuição de animês em tempos de globalização da cultura. In: Congresso de Ciências da Comunicação na Região Sudeste, 17, 2012, Ouro Preto. Anais... Ouro Preto, Intercom, 2012. 